\section{Mechanics of fluids}

Physical Fluid Dynamics. By D. J. Tritton. Pp. 362. (Van Nostrand Reinhold: New York, 1977.) Paperback £5.50.

IN principle the mechanics of simple fluids, such as air or water, should be comprehensible; the equations which govern their behaviour are well established and there is a wealth of equipment, some of great sophistication, available for the study of the macroscopic phenomena. Nevertheless, such is the complexity of motions that many of their central characteristics are still very imperfectly understood, and consequently the subject proves enormously attractive to a wide range of scientists.

The subject can be taught from various viewpoints-mathematical or engineering are the commonest-each requiring a different emphasis, although its interdisciplinary property should always be borne in mind. Introductory textbooks are available in plenty to meet in part these special needs but the present book is rather unusual in that it is directed towards physicists who are more concerned with understanding the phenomena

\section{Relativity made simple}

Tensors, Relativity and Cosmology. By Eric A. Lord. Pp. 207. (McGraw-Hill: London, New York and Toronto, 1977.) $£ 3.30$.

THERE is nothing especially new in this book, but no claim is made that there is. It is essentially a small, cheap, straightto-the-point, teaching textbook on relativity theory, and I like it. The reverse side of the title page contains the comment: "This book has been subsidised by the Government of India through the National Book Trust, India, for the benefit of the students", which can't be bad. For only $£ 3.30$ it is certain to reach its core market, which is the mathematically inclined postgraduate student with no previous knowledge of relativity.

The book is short-just 200 pagesand necessarily concise. It is divided in an obvious way into three parts: tensors (19 pages), special relativity (61 pages) and general relativity (forming the bulk of the book with 111 pages). The whole thing is broken up into no less than 15 chapters, which if nothing else makes it easily digestible to the uninitiated readers. If part $I$ is incomprehensible, the author refers us to part II.

There are, of course, quite a number of books at about this level, but Tensors, Relativity and Cosmology does have some distinguishing features to recommend it. First, it is more mathematical than many of its rivals. The treatment of tensors and differential geometry is traditional, but there is also a chapter on without subjecting themselves to the full discipline of mathematical argument. It should, however, be of interest to all beginning students because of the wide sweep of topics in each of which a number of interesting, sometimes curious and even spectacular properties are described, usually with explanations using simple mathematical or physical ideas which stimulate the reader to find out more.

The author also recognises at once the central characteristic of fluid motions, namely, their proneness to instability and turbulence. He opens with a discussion of three examples-pipe flow, bluff bodies and convection-before deriving the equations of motion and later devotes about a third of the book to a general discussion of this characteristic. It is disappointing that most of the available knowledge is phenomenological and he sadly concludes that the practical engineer uses empirical methods which have "little support from fundamental studies".

After a derivation of the Navier-Stokes equations, which is good physically but mathematically superficial, he then goes on to discuss a number of crucial concepts, vorticity, Reynolds number, inviscid flows, boundary layers and lift, with the aim of giving the student a feel for fluid motions and an appreciation of major difficulties hampering progress. Convective processes are then discussed in more detail largely from physical and dimensional points of view, followed by useful accounts of the special features of rotating and stratified flow, for example, blocking, Taylor columns and internal waves. The book ends with comments on a number of important practical situations where the ideas of fluid mechanics are of significance.

While I felt uncomfortable at some points in the text, where the explanations offered seemed as mysterious as the phenomenon, and important concepts, such as group velocity, were given inadequate treatment, the competence, range of material and infectious enthusiasm permeating the book encourage me to recommend it to mathematical and engineering students as essential general reading.

K. Stewartson

K. Stewartson is Joint Head of the Department of Mathematics at University College, London, UK. gravitation and spinors. Second, several topics are treated which do not often crop up in books as narrowly directed as this. For example, a whole chapter is devoted to unified field theories and another to scalar-tensor theories.

Inevitably in a book that covers so many topics in such a short space, depth is sacrificed to comprehensiveness. The inclusion of cosmology in the title is not really fair, as it only warrants one chapter of 18 pages, and goes little beyond what can be found in, for example, Bondi's original book. Only the standard Robertson-Walker models are discussed, with the steady-state theory packed into a couple of pages for good measure

I doubt if the author's claim that those who have mastered this book will be equipped to "carry out research in relativity and related topics" can really be justified. However, such a reader will certainly have a whetted appetite, and will wish to engage the more detailed textbooks for some of the topics only touched on here.

There will always be a market for books of this type that actually write down in the simplest possible way many of the things that have to be dug so painfully from the more pedantic works. There is the danger that it degenerates into a dry run-down of superficial facts, but I at least am pleased to have such a large amount of scattered information collected in one place. In short, a very convenient, if unexceptional book.

Paul Davies

Paul Davies is Lecturer in Mathematics at King's College, University of London, UK.

\section{BRITISH MUSEUM (NATURAL HISTORY) BOOKSHOP}

All $B M(N H)$ books and publications can be seen at the new bookshop in the Natural History Museum at South Kensington. The scientific works have now been placed in a section of their own where visitors can browse at leisure.

Students, teachers and researchers alike will find items of interest among hundreds of titles on biology, geology and mineralogy.

The shop is open during most Museum hours, including Sundays. 